\title{
Cross-Seasonal Precursors of Strong Persistent Freezing Rain and Snow Events in South and Southwest China
}

\section{Li Siyan}

Nanjing University of Information Science and Technology

Sun Xiaojuan ( $\nabla$ sxjzy709@nuist.edu.cn)

Nanjing University of Information Science and Technology

Julian X.L. Wang

NOAA Air Resources Laboratory

Chen Li

Nanjing University of Information Science and Technology

\section{Research Article}

Keywords: freezing rain and snow events, warning signs, climate prediction, air-sea interaction, southern China.

Posted Date: January 31st, 2022

DOI: https://doi.org/10.21203/rs.3.rs-1293986/v1

License: (c) (i) This work is licensed under a Creative Commons Attribution 4.0 International License. Read Full License 


\section{Cross-seasonal precursors of strong persistent freezing rain and snow} events in south and southwest China

3

4

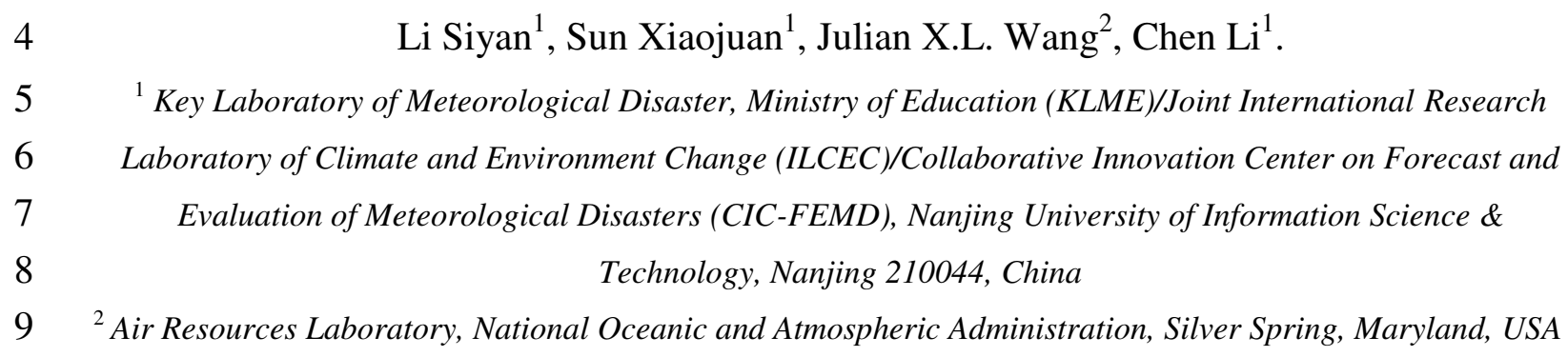

${ }^{1}$ Key Laboratory of Meteorological Disaster, Ministry of Education (KLME)/Joint International Research

6 Laboratory of Climate and Environment Change (ILCEC)/Collaborative Innovation Center on Forecast and Evaluation of Meteorological Disasters (CIC-FEMD), Nanjing University of Information Science \& Technology, Nanjing 210044, China

$9{ }^{2}$ Air Resources Laboratory, National Oceanic and Atmospheric Administration, Silver Spring, Maryland, USA

5 10

$11 \quad$ Corresponding author: Sun Xiaojuan, sxjzy709@nuist.edu.cn 


\section{Abstract}

14 We used daily temperature and precipitation data from 753 stations provided by the National Meteorological 15 Information Center of China for the time period 1950-2018 and NCEP/NCAR reanalysis data to explore winter weather events in southwest China $\left(100-110^{\circ} \mathrm{E}, 22.5-32.5^{\circ} \mathrm{N}\right)$. We found a cross-seasonal precursor signal for the occurrence of freezing rain and snow events. Key zones of the tropical Pacific $\left(160^{\circ} \mathrm{E}-90^{\circ} \mathrm{W}, 5^{\circ} \mathrm{S}-5^{\circ} \mathrm{N}\right)$ sea surface temperature (SST), the north Pacific decadal oscillation (PDO)-like SST mode and the Indian Ocean $\left(40-100^{\circ} \mathrm{E}, 10^{\circ} \mathrm{S}-20^{\circ} \mathrm{N}\right) \mathrm{SST}$ in the previous autumn were significantly correlated with the key anomaly combination index in winter. Forcing of the atmosphere by these three key areas in terms of SST led to significant atmospheric circulation anomalies in the north Pacific and its lower reaches. The coupling effect of the cold SST at $\left(160^{\circ} \mathrm{E}-90^{\circ} \mathrm{W}, 5^{\circ} \mathrm{S}-5^{\circ} \mathrm{N}\right)$ and the north Pacific PDO-like cold SST mode in the previous autumn caused an abnormal longwave disturbance over the north Atlantic Ocean in winter, which was dispersed downstream. This caused mid- to high-latitude circulation anomalies in East Asia that favored the diffusion of cold air. The cold SST at $\left(40-100^{\circ} \mathrm{E}, 10^{\circ} \mathrm{S}-20^{\circ} \mathrm{N}\right)$ deepened the southern branch trough, favoring the occurrence of freezing rain and snow events. The CESM air-sea coupling model simulated the forcing effect outside the three key areas of SST in November, consistent with the observed statistical results. An inter-seasonal prediction index for strong persistent freezing rain and snow events in southwestern China was established based on the average SST anomalies in key areas in the previous November. This index provides a reference for the inter-seasonal prediction of winter freezing events in southern China.

Keywords: freezing rain and snow events, warning signs, climate prediction, air-sea interaction, southern China.

\section{Introduction}

Low temperatures and freezing rain and snow events during the winter months cause varying degrees of disruption in China, especially in the south of the country. These adverse weather events can affect transportation, energy, agriculture, communications and electricity, and may even lead to the loss of lives and livelihoods, causing serious economic losses (Wang et al., 2008; Wu et al., 2008; Zhou et al., 2008; Yao et al., 2012). The occurrence of freezing rain and snow events requires specific temperatures and water vapor conditions. The northern region of China is restricted by precipitation conditions, whereas the southern region is subject to temperature controls. The northern region of China is therefore more affected by cold wave processes, whereas freezing rain and snow events mainly occur in southern China (Qian, 2013). Persistent freezing rain and snow events in southern China generally refer to long-lasting intense cooling and precipitation processes. The occurrence of such events requires the long-term maintenance or oscillations of cold air activity and suitable water vapor and dynamic conditions. (He and Sun, 2017; Liao, 2017).

Much research has been carried out on the possible precursor signals of typical low-temperature rain and snow weather. For example, during the low-temperature freezing weather in January 2008, deepening of the southern branch trough and maintenance of the subtropical high, which are closely related to this weather process, were caused by the Rossby wave energy in the northeast Atlantic and western Europe propagating downstream along the Asian-African subtropical jet (Bueh et al., 2008; Shi et al., 2008; Ji et al., 2008). Zhang and Zhang (2013) found that the full wind speed and zonal components of the subtropical and temperate jets show clear signs that continuous low-temperature rain and snow will begin two weeks after. 
Bo Sun et al. (2018) showed that the cold air activity during snowfall in East China in January 2018 was related to an early reduction in Arctic sea ice in the Kara and Barents seas. By contrast, the transportation of water vapor in the south was significantly related to the northwest Pacific (La Niña) and Atlantic Ocean. However, the mechanism by which air-sea interactions in the Atlantic Ocean affect snowfall processes is still unclear.

Some researchers have discussed the precursor signals of multiple freezing rain and snow weather events. For example, Wang et al. (2011) studied 19 years of severe ice and snow disasters in southern China and showed that the Antarctic oscillation affected sea surface temperatures (SSTs) in the South Indian Ocean two months in advance. The SST increased abnormally and ice and snow disasters occurred in the following year. Jiang et al. (2014) decomposed the global atmospheric variable data for 23 low-temperature rain, snow and freezing events that occurred in southern China from 1960 to 2008. They obtained the synoptic-scale disturbance component and used it to analyze the early signals for low-temperature freezing rain and snow events. They found that before the freezing event, the largest negative disturbance in altitude above southern China occurred at $300 \mathrm{hPa}$ and that there was also a negative temperature disturbance at $850 \mathrm{hPa}$.

Wang et al. (2016) studied the relationship between persistent low-temperature rain and snow events and transient, weather-scale disturbances in southern China by analyzing typical low-temperature rainy and snowy years and high-temperature, less rainy and snowy years in January. They found that there were strong weather-scale disturbances over the Atlantic Ocean. Transient disturbances propagated downstream in the form of wave trains in Eurasia. The eastward dispersion of wave energy provided a continuous source of energy for downstream trough and ridge activities, which favored the maintenance of atmospheric baroclinic instability and continuous low-temperature rain in southern China. Most of the existing studies of the precursor signals of freezing rain and snow are mostly qualitative studies of a few events and have proposed possible signals indicating the occurrence of events, including intra-seasonal and high-altitude atmospheric signals and cross-seasonal, forced SST signals outside areas of sea ice.

Sun (2021) and others have classified continuous freezing rain and snow events in southwestern China into three categories (high-frequency, long duration and strong intensity events) that are meaningful for the short-term prediction of these events After a long period of development, there has been great progress in short-term climate prediction technologies and methods. New forecasting technologies and understanding of mechanisms have been applied to short-term climate forecasting operations. For example, new knowledge of the global ocean, Arctic sea ice, Eurasian snow and the influence of the circulation system in the southern hemisphere on the East Asian monsoon has been introduced into short-term climate predictions (Liu et al, 2003, Jia et al., 2013; Li et al., 2013). An understanding of the relationship between external forcing factors (e.g., SSTs, sea ice and the East Asian monsoon) will help us to explore the influence of external forcing on persistent freezing rain and snow events in southwestern China. The application of new knowledge will greatly improve the short-term prediction of persistent freezing rain and snow events in southern China.

87

\section{$88 \quad 2$ Data and methodology}

\subsection{Datasets}


The data examined in this research were daily temperature and precipitation taken from 753 stations across China, provided by China National Meteorological Information Center from 1950 to 2018 (http://data.cma.cn). In addition, monthly and daily NECP/NCAR reanalysis data were examined with a mesh accuracy of $2.5^{\circ} \times 2.5^{\circ}$ and vertical levels in the range 1000-300 $\mathrm{hPa}$. The examined variables were horizontal wind, vertical wind speed, geopotential height, temperature, relative humidity and absolute humidity (https://www.esrl.noaa.gov).

\subsection{Freezing index}

Station freezing days in southern China were defined as station daily mean temperature less than $1.0^{\circ} \mathrm{C}$ with the presence of precipitation. If the freezing days continue three days at least, the period is identified as a persistent freezing rain and snow weather event (Wang, 2008; Wang, 2011). For each freezing rain and snow event, the freezing index $\mathrm{Z}$ can be calculated using the following equations:

$$
\begin{aligned}
& \mathrm{I}_{\mathrm{ij}, 1}=\frac{\mathrm{d}_{\mathrm{ij}}-\mathrm{d}_{\text {min }}}{\mathrm{d}_{\text {max }}-\mathrm{d}_{\text {min }}} \\
& \mathrm{I}_{\mathrm{ij}, 2}=\frac{\mathrm{r}_{\mathrm{ij}}-\mathrm{r}_{\text {min }}}{\mathrm{r}_{\max }-\mathrm{r}_{\text {min }}} \\
& \mathrm{I}_{\mathrm{ij}, 3}=-\frac{\overline{\mathrm{t}}_{\mathrm{ij}}-\overline{\mathrm{t}}_{\text {min }}}{\overline{\mathrm{t}}_{\text {max }}-\overline{\mathrm{t}}_{\text {min }}} \\
& \mathrm{I}_{\mathrm{ij}, 4}=-\frac{\mathrm{tl}_{\mathrm{ij}}-\mathrm{t}_{\text {min }}}{\mathrm{t}_{\mathrm{max}}-\mathrm{tl}_{\text {min }}}=\frac{\mathrm{I}_{\mathrm{ij}, 1}}{\overline{\mathrm{I}}_{1}}+\frac{\mathrm{I}_{\mathrm{ij}, 2}}{\overline{\mathrm{I}_{2}}}+\frac{\mathrm{I}_{\mathrm{ij}, 3}}{\overline{\mathrm{I}}_{3}}+\frac{\mathrm{I}_{\mathrm{ij}, 4}}{\overline{\mathrm{I}_{4}}}
\end{aligned}
$$

where $d$ is the duration of the weather conditions in days; $i$ is the sequence number of stations; $j$ is the sequence number of freezing rain and snow events; $d_{\max }$ and $d_{\min }$ are the maximum and minimum weather duration of the weather conditions in days for all events, respectively; $r$ is the total precipitation during the event; and $r_{\max }$ and $r_{\min }$ are the maximum and minimum total precipitation across all events, respectively; tis the average temperature of the event; $\bar{t}_{\max }$ and $\overline{\mathrm{t}}_{\min }$ are the highest and lowest average temperature across all events, respectively; $t \mathrm{l}$ is the minimum temperature of the event; and $t l_{\max }$ and $t l_{\min }$ are the highest and lowest event minimum temperatures across all events, respectively.

$\mathrm{I}_{\mathrm{ij}, 1}, \mathrm{I}_{\mathrm{i}, 2,2}, \mathrm{I}_{\mathrm{ij}, 3}, \mathrm{I}_{\mathrm{ij}, 4}$, are the average values of four factors, include freezing persistent days, total precipitation, average temperature and minimum temperature, respectively. $Z_{\mathrm{ij}}$ is the comprehensive freezing weather process index in South China (abbreviated as freezing index). Using $Z_{\mathrm{ij}}$ to calculate the annual average can obtain an annual series of freezing index, as $\mathrm{Z}$.

112 In this paper, this method was used to calculate the winter freezing index in southwest China $\left(100^{\circ} \mathrm{E}-\right.$ $113110^{\circ} \mathrm{E}, 22.5^{\circ} \mathrm{N}-32.5^{\circ} \mathrm{N}$ ) and obtain the southwest China regional average annual series, $\mathrm{Z}_{\mathrm{SW}}$, which was used to 114 characterize the intensity of freezing rain and snow events in southwest China in winter during 1951-2017. In 115 addition, the strong years and processes of freezing rain and snow events were screened (Table1), where start 116 date was defined as the first date in which at least $20 \%$ of stations in southwest China suffer from freezing rain 117 and snow events and the end date is the day before the number of freezing stations in the southwest region 
118 decreases to less than $20 \%$ during an event. The outbreak date is a day in which the total number of freezing

119 affected stations reaches the peak. The 13 strong freezing rain and snow events in southwest China generally

120 lasted for an average of about 17.5 days, and most of the events occurred in January and February of the

121 following year after December. On the outbreak day of the event, the precipitation in southern China was

122 exceptionally high (Fig1).

123

124 Table 1 Strong persistent freezing rain and snow events in southwest China in winters of 1951-2017.

\begin{tabular}{lllll}
\hline Start & End & Outbreak & $\begin{array}{l}\text { Duration } \\
(\text { days })\end{array}$ & $\begin{array}{l}\text { Freezing } \\
\text { index }\end{array}$ \\
\hline $1954-12-23$ & $1955-01-06$ & $1954-12-28$ & 15 & 25 \\
$1956-01-18$ & $1956-02-04$ & $1956-01-30$ & 16 & 24 \\
$1957-02-08$ & $1957-02-28$ & $1957-02-20$ & 21 & 32 \\
$1958-02-03$ & $1958-02-21$ & $1958-02-05$ & 19 & 31 \\
$1959-02-14$ & $1959-02-28$ & $1959-02-16$ & 15 & 25 \\
$1968-01-29$ & $1968-02-13$ & $1968-02-05$ & 16 & 24 \\
$1972-02-01$ & $1972-02-10$ & $1972-02-03$ & 10 & 24 \\
$1982-02-03$ & $1982-02-16$ & $1982-02-05$ & 14 & 23 \\
$1984-01-15$ & $1984-02-12$ & $1984-01-16$ & 29 & 44 \\
$1995-02-13$ & $1995-02-28$ & $1995-02-19$ & 16 & 21 \\
$2000-01-24$ & $2000-02-05$ & $2000-01-28$ & 13 & 20 \\
$2000-02-19$ & $2000-02-29$ & $2000-02-25$ & 11 & 21 \\
$2008-01-12$ & $2008-02-14$ & $2008-01-13$ & 33 & 59 \\
\hline
\end{tabular}

125

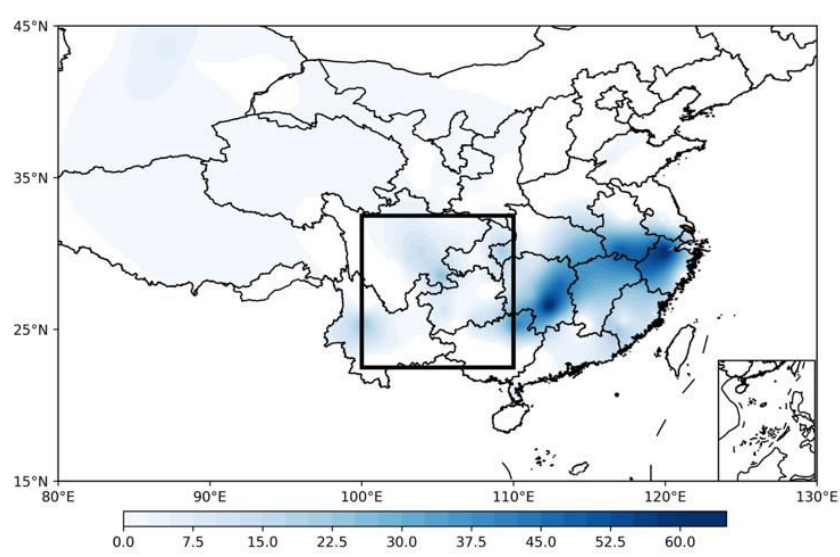



events.

\section{$130 \quad$ 2.3 Station PT index}

131 Station PT index (precipitation and temperature index) (Zhang, 2011) is the difference between 132 precipitation and temperature after standardization, which emphasizes the equal importance of precipitation and 133 temperature. It was determined as follows:

$$
\mathrm{PT}_{\mathrm{i}}=\frac{\mathrm{P}_{\mathrm{i}}-\overline{\mathrm{p}}}{\mathrm{p}_{\mathrm{s}}}-\frac{\mathrm{T}_{\mathrm{i}}-\overline{\mathrm{T}}}{\mathrm{T}_{\mathrm{s}}}
$$

134 where $P_{i}$ and $T_{i}$ are the average monthly precipitation and surface temperature in southern China, 135 respectively; $\bar{p}$ and $\mathrm{T}$ are the average precipitation and temperature in the same period of history, respectively; 136 and $\mathrm{p}_{\mathrm{s}}$ and $\mathrm{T}_{\mathrm{s}}$ are the standard deviations of precipitation and temperature in the same period of history, 137 respectively. In this paper, the method was modified to:

$\mathrm{PT}_{\mathrm{ij}}=\frac{\mathrm{P}_{\mathrm{ij}}-\overline{\mathrm{p}}}{\mathrm{p}_{\mathrm{s}}}-\frac{\mathrm{T}_{\mathrm{ij}}-\overline{\mathrm{T}}}{\mathrm{T}_{\mathrm{s}}}$

138 where $P_{i j}$ and $T_{i j}$ are the daily precipitation and surface temperature at Station $j$ on Day i, respectively; $\bar{p}$

139 and $\overline{\mathrm{T}}$ are the average of precipitation and temperature in the same period of history, respectively; and $\mathrm{p}_{\mathrm{s}}$ and $140 \mathrm{~T}_{\mathrm{s}}$ are the standard deviation of precipitation and temperature in the same period of history, respectively. Here,

$141 \mathrm{PT}_{\mathrm{ij}}$ index is used in to represent the intensity of precipitation and temperature change during a freezing rain 142 and snow event.

\section{2.4 Mongolia high pressure circulation index}

144 The Mongolian high pressure intensity index $P$, area index $S$ and central position index $\left(\lambda_{c}, \varphi_{c}\right)$ were 145 calculated according to the universal definition method for a circulation index of closed pressure system 146 proposed by Wang et al. (2007) and the set of Mongolian high pressure circulation indexes defined by Liu et al. 147 (2011). For the $1000 \mathrm{hPa}$ isobaric surface in the number $\mathrm{t}$ year, for year $\mathrm{t}$ where $\mathrm{t}$ is 1951 to 2017, the three 148 circulation indexes of the Mongolian high were identified as follows: (1) the area index $S(t)$ is the area of the 149 region, which is surrounded by a computational field $\mathrm{D}(\mathrm{t})$ in a sphere of unit radius search area $\Omega$; (2) intensity 150 index $\mathrm{P}(\mathrm{t})$ is defined as the surface integral of geopotential height difference $\Delta H(t)=H(t)-f_{0}$ in the $D(t)$; and 151 (3) the center position index $\left(\lambda_{c}(t), \varphi_{c}(t)\right)$ is the latitude and longitude of the gravity field center corresponding 152 to $\Delta \mathrm{H}(\mathrm{t})$ over the region $\mathrm{D}(\mathrm{t})$. Liu (2011) showed that the search area $\Omega$ used in the calculation of Mongolian 153 high pressure is $60^{\circ} \mathrm{E}-130^{\circ} \mathrm{E}$ and $20^{\circ} \mathrm{N}-70^{\circ} \mathrm{N}$. The characteristic contour (December-February) is $154 \mathrm{f}_{0}=220 \mathrm{gpm}$. 


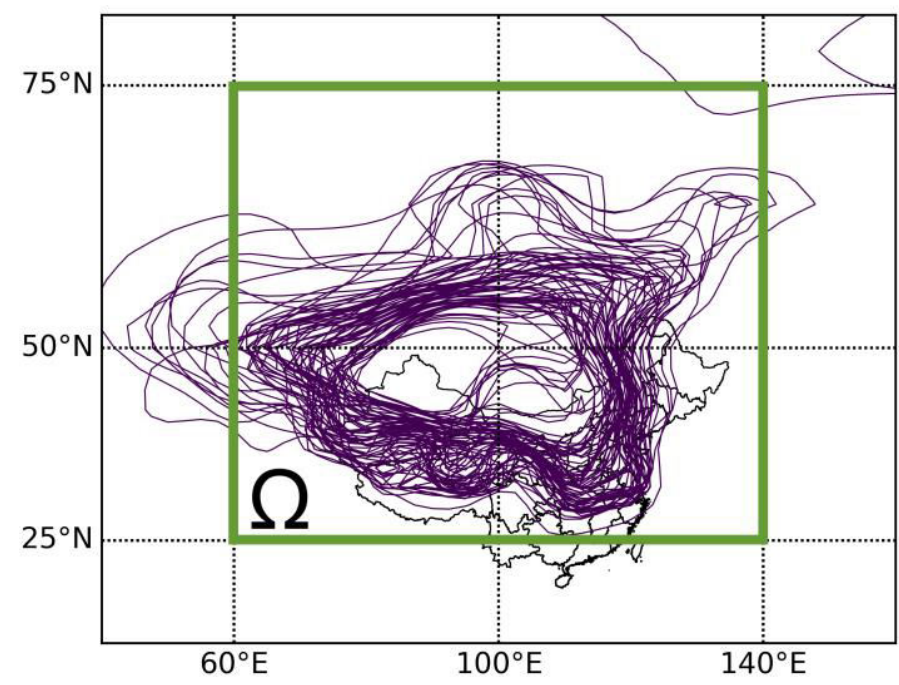

Fig.2 Mongolian high pressure search area $\Omega$ and the winter characteristic contour $\mathrm{f}_{0}=220 \mathrm{gpm}$ from

\section{Analysis of Inter-seasonal Precursor Signals of Strong Persistent Freezing}

\section{Rain and Snow Events in Southwest China}

Existing studies have shown that the significant impact systems closely related to the occurrence of persistent freezing rain and snow events in southwestern China include the Mongolian high and the south branch trough. An abnormal combination index $\left(P_{\mathrm{CA}}\right)$ can be established by using multiple linear regression methods and the Mongolian high pressure strength index, the north-south position index and the south branch trough strength index key. When $P_{\mathrm{CA}}$ increases (decreases), this indicates that the Mongolian high pressure is stronger (weaker), more southerly (northerly) and that the south branch trough is stronger (weaker). These conditions favor cooling (increasing temperatures) and an increase (decrease) in precipitation in southwest China. The key anomaly combination index $P_{\mathrm{CA}}$ can be used as a link to explore the precursor signals of persistent freezing rain and snow events in southwest China (Sun, 2021).

\subsection{Relationship Between SSTs in Autumn and Winter and Key Anomaly}

\section{Combinations in Winter}

Using the key anomaly combination index in winter regressed upon the SST anomaly (SSTA) field in autumn and winter showed that there was a significant anomaly in the Pacific SST field in southwestern China during strong years with heavy rain and snow events in autumn and winter (Fig3). Significant negative SSTAs (La Niña) were present in the tropical NINO3 and NINO4 areas $\left(160^{\circ} \mathrm{E}-90^{\circ} \mathrm{W}, 5^{\circ} \mathrm{S}-5^{\circ} \mathrm{N}\right)$ and the SSTA reached its lowest value of less than $-0.5^{\circ} \mathrm{C}$ in November. The mid-latitude SST field of the North Pacific Ocean east of Japan to $30^{\circ} \mathrm{W}$ showed positive SSTAs from the previous October, with a significant anomaly center at $30-40^{\circ} \mathrm{N}$ to the south of the Aleutian arc. The Gulf of Alaska along the eastern coast of the North 

decadal oscillation (PDO) cold (negative) phase. This SST mode persisted from October to November. The PDO-like SST mode gradually collapsed in winter as the warm SST center of the North Pacific Ocean developed toward the northeast coast of North America. There were significant and consistent negative SSTAs in the North Indian Ocean $\left(40-100^{\circ} \mathrm{E}, 10^{\circ} \mathrm{S}-20^{\circ} \mathrm{N}\right)$ in autumn and winter.

(a)

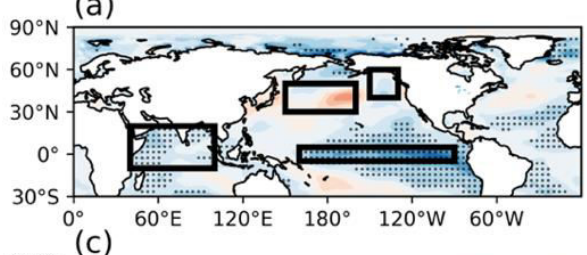

$90^{\circ} \mathrm{N}$ (c)

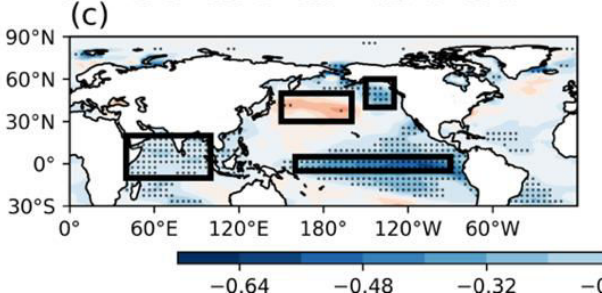

(b)

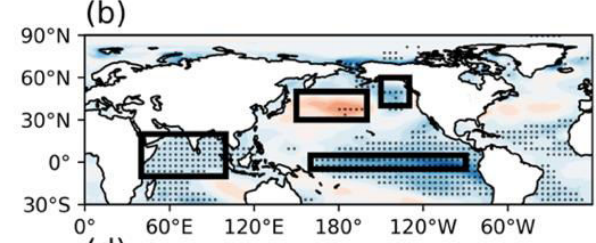

(d)

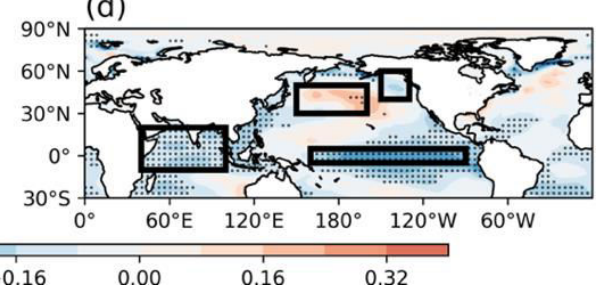

Fig.3 Regression of the key anomaly combination index in winter from 1951 to 2017 on the SSTA field (units: ${ }^{\circ}$ C). a September SSTA; $\mathbf{b}$ October SSTA; $\mathbf{c}$ November SSTA; and $\mathbf{d}$ winter average SSTA. The dots show where the results passed the significance test at $\alpha=0.01$.

Table2 gives the correlation coefficient between the SST models for each regional index and the key abnormal combination index. These results indicate the possible connections between the SSTAs in the three key areas in the previous period and the atmospheric circulation factors (the Mongolian high pressure and the southern branch trough) that favor the occurrence of freezing rain and snow events in southwest China in winter. The tropical Pacific SST index (SST1) is a standardized average SSTA. A positive (negative) index indicates a higher (lower) SST in the tropical Pacific $\left(5^{\circ} \mathrm{S}-5^{\circ} \mathrm{N}, 160^{\circ} \mathrm{E}-90^{\circ} \mathrm{W}\right)$. The SST2 index of the north Pacific SST mode is the normalized time series of the anomaly of the difference between the average SST at $\left(20-70^{\circ} \mathrm{N}\right.$, $\left.110^{\circ} \mathrm{E}-100^{\circ} \mathrm{W}\right)$ and the average $\mathrm{SST}$ at $\left(130-150^{\circ} \mathrm{W}, 40-60^{\circ} \mathrm{N}\right)$. If the index is positive (negative), then the Pacific SST in the northeastern sea area of the north Pacific is higher (lower) and the Pacific SST in the southwestern sea area is lower (higher). The Indian Ocean SST index (SST3) is a standardized $\left(10^{\circ} \mathrm{S}-20^{\circ} \mathrm{N}\right.$, $40-100^{\circ}$ E) average SSTA. A positive (negative) index indicates a high (low) Indian Ocean SST.

The results of the correlation coefficient showed that the previous SST index (SST2 in October and November, SST1 and SST3 in summer and autumn) and the key abnormal combination index were significantly negatively correlated. The correlation between SST1 and SST3 and the key anomaly combination index in autumn was significantly better than that in summer and the correlation coefficients were all less than -0.5 . The tropical Pacific cold (warm) SST mode in the previous autumn and the development of the Indian Ocean uniform cold (warm) SST mode strengthened (weakened) the Mongolian high pressure in winter and strengthened (weakened) the southern branch trough. The SST2 in the previous November had the best correlation with the key anomaly combination index $(-0.396)$. The cold (warm) SST in the northeastern North 
Pacific and the (warm) cold SST in the southwestern sea developed in November, the Mongolian high pressure

210 strengthened (weakened) in winter and south branch trough strengthened (weakened).

211 Twelve severe persistent freezing rain and snow events occurred in the southwestern region in the middle

212 of the year and in 10 of these 12 years the tropical Pacific SST was colder in November. The north Pacific SST2

213 index was negative in November and December, and the Indian Ocean SST2 was colder in November of August

21412 (Fig4). This shows that the forcing effect of the coupled SST modes of the autumn tropical Pacific SST

215 anomaly, the cold northeast-warm southwest north Pacific SST and the Indian Ocean negative SST anomaly on

216 the atmosphere may have disturbed the atmospheric geopotential height over East Asia in winter. Because the

217 three key zone indexes of the SST in the previous autumn and November had a good correlation with the key

218 winter anomaly combination index (the correlation coefficients were $-0.507,-0.396$ and -0.531 , respectively),

219 we used the SST field in November to discuss the physical mechanism of the prediction index.

\subsection{Forcing Mechanism of the November SSTA on the Winter Atmosphere}

Much research has been published on the response of the atmospheric circulation to thermal forcing by the ocean. The negative phase of the El Niño Southern Oscillation (ENSO) (La Niña) favors strengthening of the

223 East Asian winter monsoon, which affects winter temperatures and precipitation in China (He and Ding, 2008; Zhou and Wu, 2010; Wang and He, 2012; He and Wang, 2013). Coupling of the negative phase of the PDO and the ENSO has a strong impact on the East Asian monsoon and significant temperature changes occur in East Asia (Wang, et al., 2008). Most areas of China experience more precipitation in a La Niña year when the PDO is in the negative phase (Topaz, 2016). The SST in the tropical Indian Ocean may affect precipitation in southern China by affecting the Hadley circulation (Deng et al., 1989; Suo et al., 2009). When the Indian Ocean SST changes uniformly, the temperature in China also changes uniformly (Tang and Sun, 2007).

Cold SST anomalies occurred in the tropical Pacific Ocean in the autumn before years in which strong persistent freezing rain and snow events occurred in southwest China in winter (La Niña). The SST of the north Pacific Ocean was colder in the northeast while the southwestern sea area was warmer, similar to the cold phase of the PDO. The SST of the north Indian Ocean was uniformly colder. The November SST indices SST1, SST2 and SST3 were significantly related to the winter key anomaly combination index. Coupling of the three SST zone modes may therefore be a precursor signal of continuous freezing rain and snow events in southwest China in winter. To clarify the possible mechanism of influence of the November SST anomaly on the winter atmosphere, SST1, SST2, and SST3 were regressed onto the winter height field, circulation field and flow function field, respectively.

239

Table 2 Correlation coefficients between the SST indices from summer to autumn and the key anomaly combination indices in winter.

\begin{tabular}{|c|c|c|c|c|c|c|}
\hline Month & 6 & 7 & 8 & 9 & 10 & 11 \\
\hline SST1 & $-0.376^{*}$ & $-0.452^{2}$ & $-0.478^{*}$ & $-0.561^{*}$ & $-0.500^{*}$ & $-0.507^{*}$ \\
\hline SST2 & -0.205 & -0.264 & -0.206 & -0.151 & $-0.378^{*}$ & $-0.396^{*}$ \\
\hline SST3 & $-0.437^{*}$ & $-0.456^{*}$ & $-0.454^{*}$ & $-0.545^{*}$ & $-0.541^{*}$ & $-0.531^{*}$ \\
\hline
\end{tabular}




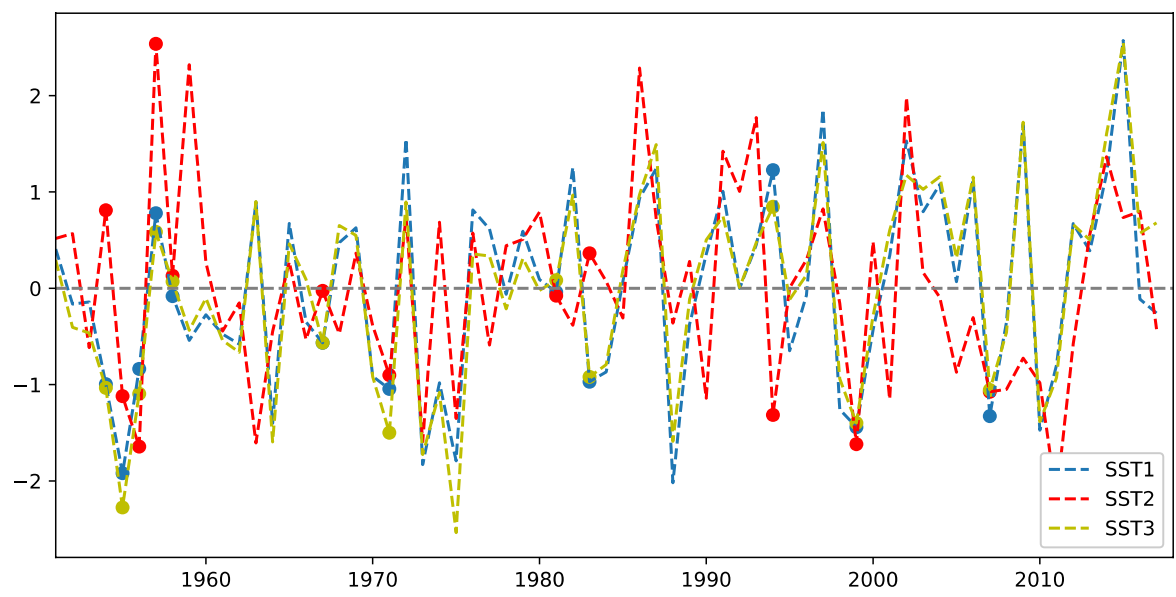

Fig.4 Standardized SST1, SST2 and SST3 indices from 1951 to November 2017. The points show years with strong persistent freezing rain and snow events in southwest China.

\section{1) Forcing Effect of SSTs on the Atmosphere in a Key Area of the Tropical Pacific}

If the SST in the tropical Pacific from autumn to winter continued to be low, thermal forcing increased sinking in the eastern equatorial Pacific and the Walker circulation was strengthened. This, in turn, strengthened the low-level easterly wind anomaly at the equator $120^{\circ} \mathrm{E}-120^{\circ} \mathrm{W}$ (Fig5b) and ascending movement in the western equatorial Pacific $\left(150^{\circ} \mathrm{E}-180^{\circ}\right)$. As a result, the lower troposphere from the East Asian tropical to subtropical region showed a significant negative height anomaly, which favored the southward transport of cold air from northern East Asia (Fig5a).

By contrast, thermal forcing of the cold SST in the tropical Pacific weakened the Hadley circulation in the tropical Pacific (Fig5c), which, in turn, weakened the sinking branch of the Hadley circulation in the subtropical region $\left(30^{\circ} \mathrm{N}\right)$, favoring elevation of the geopotential height of the lower troposphere in subtropical East Asia. At the same time, the mid-latitude Ferrer circulation weakened. Weakening of the ascending branch of the high-latitude Ferrer circulation favored the accumulation of atmospheric quality in the troposphere at this latitude, which was manifested as an anomalous positive geopotential height. The circulation in the lower troposphere from East Asia to the north Pacific at mid- to high latitudes $\left(30-60^{\circ} \mathrm{N}\right)$ was high in the north and low in the south, which favored the transport of cold air from the Far East to the mid- and low latitudes of East 


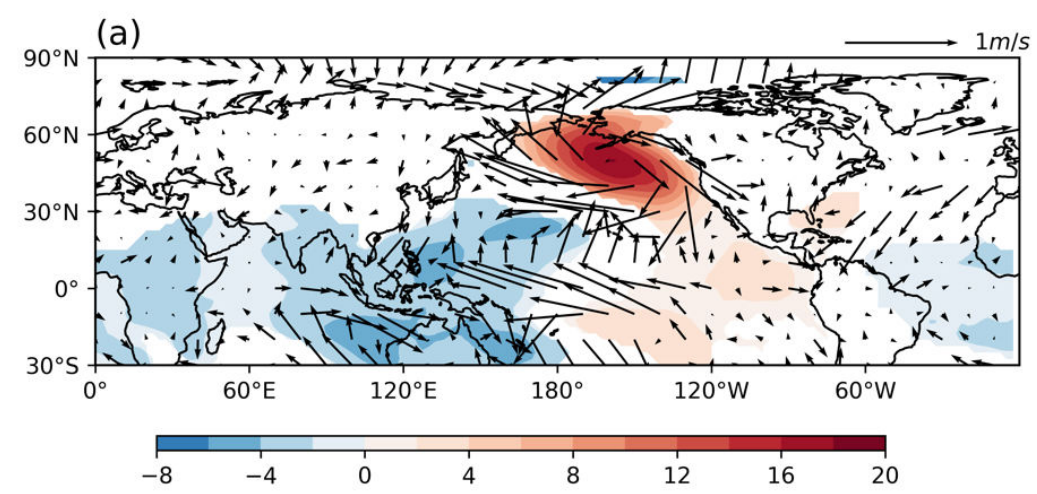

(b)
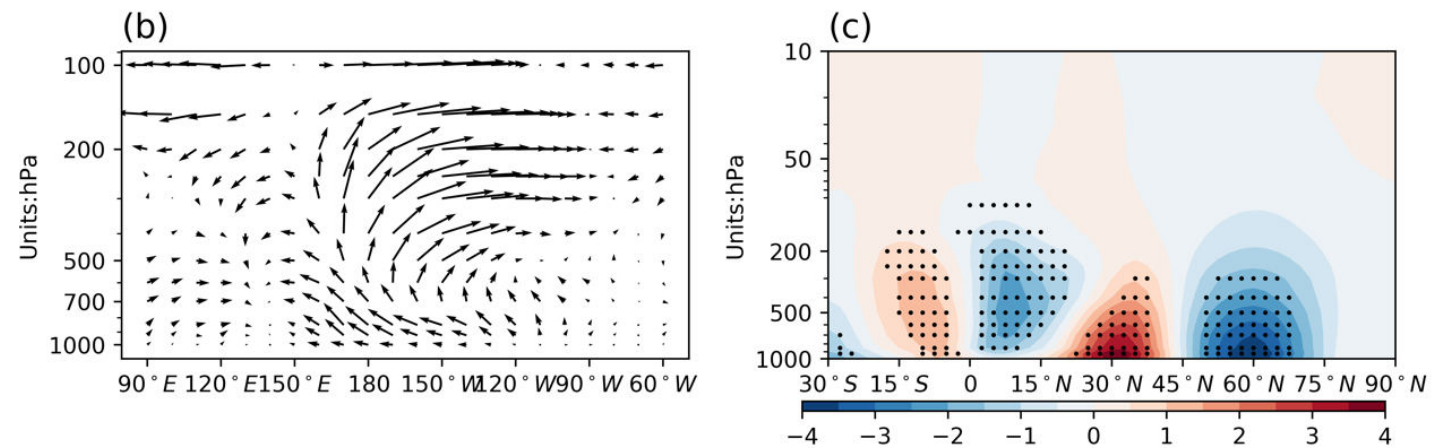

Fig.5 SST1 index in November regressed upon the strong years of freezing rain and snow events in southwest China. a The $1000 \mathrm{hPa}$ height anomaly in winter (units: gpm) and the circulation anomaly field (units: $\mathrm{m} / \mathrm{s}$ ). Filled contours indicate passing the significance test of $\alpha=0.01$. b The zonal circulation anomaly field in the equatorial area in winter (units: $\mathrm{m} / \mathrm{s}$ ). $\mathbf{c}$ The $160^{\circ} \mathrm{E}-90^{\circ} \mathrm{W}$ average current function anomaly field in the western Pacific Ocean (units: $1010 \mathrm{~kg} / \mathrm{s}$ ). Dots indicate passing the significance test of $\alpha=0.01$.

\section{2) Forcing Effects on the Atmosphere in the Key Area of SST Anomalies in the North Pacific}

The overall north Pacific SST field in the previous autumn November was colder in the northeast and warmer in the southwest during the strong years of persistent freezing rain and snow events in southwest China.

274 The southwest ocean was warmer, showing an SST mode similar to the cold phase of the north PDO. The area of the north Pacific Ocean south of $45^{\circ} \mathrm{N}$ and the lower layers of the western sea area were affected by continuous thermal forcing of the SST in the former autumn and showed a reduction in the geopotential height in winter. There was coupling between forcing of the cold SST in the center of the area from 45 to $60^{\circ} \mathrm{N}$ and in Alaskan waters and weakening of the ascending branch of the Ferrer circulation forced by the cold SST in the tropical Pacific. As a result, the central and eastern Aleutian region showed a significantly positive height anomaly (Fig6).

The longwave energy excited by the SST anomaly mode in the north Pacific dispersed upward (Fig7). The most significant upload of wave energy occurred at $45-65^{\circ} \mathrm{N}$ and the Eliassen-Palm flux (EPF) was transported to the tropopause. The longwave energy excited in the area south of $45^{\circ} \mathrm{N}$ started to disperse toward the equator after being uploaded to a certain height. The wave energy uploaded near $60^{\circ} \mathrm{N}$ deepened and maintained the height disturbance of the mid- and high levels (Fig6ab), whereas the high-latitude area north of $45^{\circ} \mathrm{N}$ (low-latitude area south of $45^{\circ} \mathrm{N}$ ) in the north Pacific can be regarded as the source (sink) of the overall wave 
energy. The EPF divergence was positive (negative), the wave flux diverged (converged) and the westerly wind accelerated (decelerated).

As a result of the acceleration of the westerly winds in the mid- and upper troposphere at high latitudes in the Pacific and strengthening of the abnormal high pressure, the development of a tropospheric obstruction in this area made it difficult for the tropospheric polar vortex to extend south over the north Pacific downstream of the North America-Iceland region. The geopotential height of the mid- and upper troposphere in this area was reduced, which was manifested as a significant abnormal anticyclonic circulation leading to deepening of the North American trough (Fig6ab). The average zonal wind speed at $200 \mathrm{hPa}$ at $70^{\circ} \mathrm{N}$ in the North Pacific during the winter from 1951 to 2017 was significantly negatively correlated with the height of the lower North America-Iceland region and there was a significant positive correlation with the altitude over Europe on the eastern coast of the North Atlantic (Fig7c). This was due to the acceleration of westerly winds in the mid-and upper troposphere in the high latitudes of the Pacific and the high-pressure obstruction that deepened the North American trough. The abnormal configuration of the circulation meant that the air mass accumulated at the bottom of the trough (western coast of the Atlantic Ocean) and in front of the trough (eastern coast of the Atlantic Ocean-Europe), showing a positive height anomaly. Anomalous wave trains of positive (western coast of the Atlantic Ocean)-negative (Greenland, Iceland)-positive (European coast of the North Atlantic) appeared over the North Atlantic. The wave train continued to disperse downstream, which eventually led to an increase in the Mongolian high pressure on the ground downstream and deepening of the southern branch trough. This eventually led to the occurrence of the freezing rain and snow events.
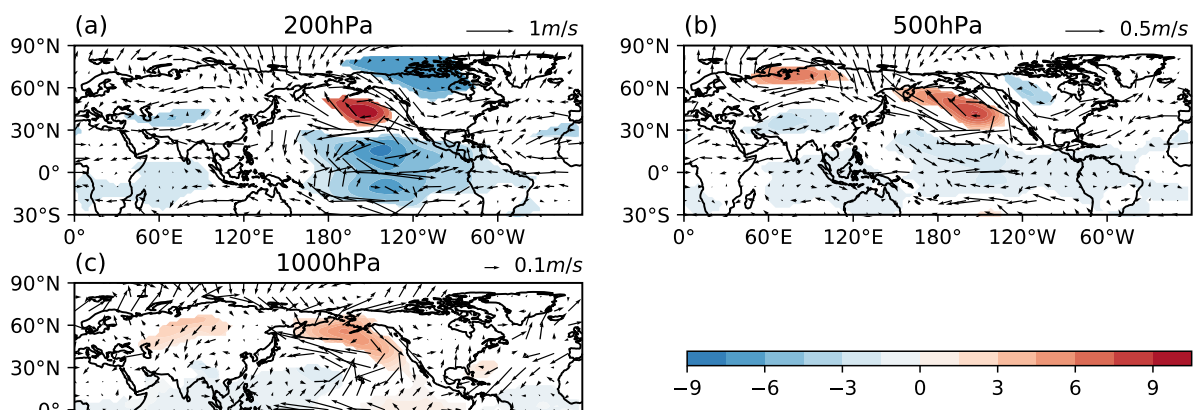

Fig.6 Regression of the SST2 index in November on the strong annual winter height anomaly (units: gpm) and circulation anomaly (units: $\mathrm{m} / \mathrm{s}$ ) of persistent freezing rain and snow events in southwestern China at a 200 $\mathrm{hPa}, \mathbf{b} 500$ and $\mathbf{c} 1000 \mathrm{hPa}$. Contours indicate passing the significance test of $\alpha=0.01$. 

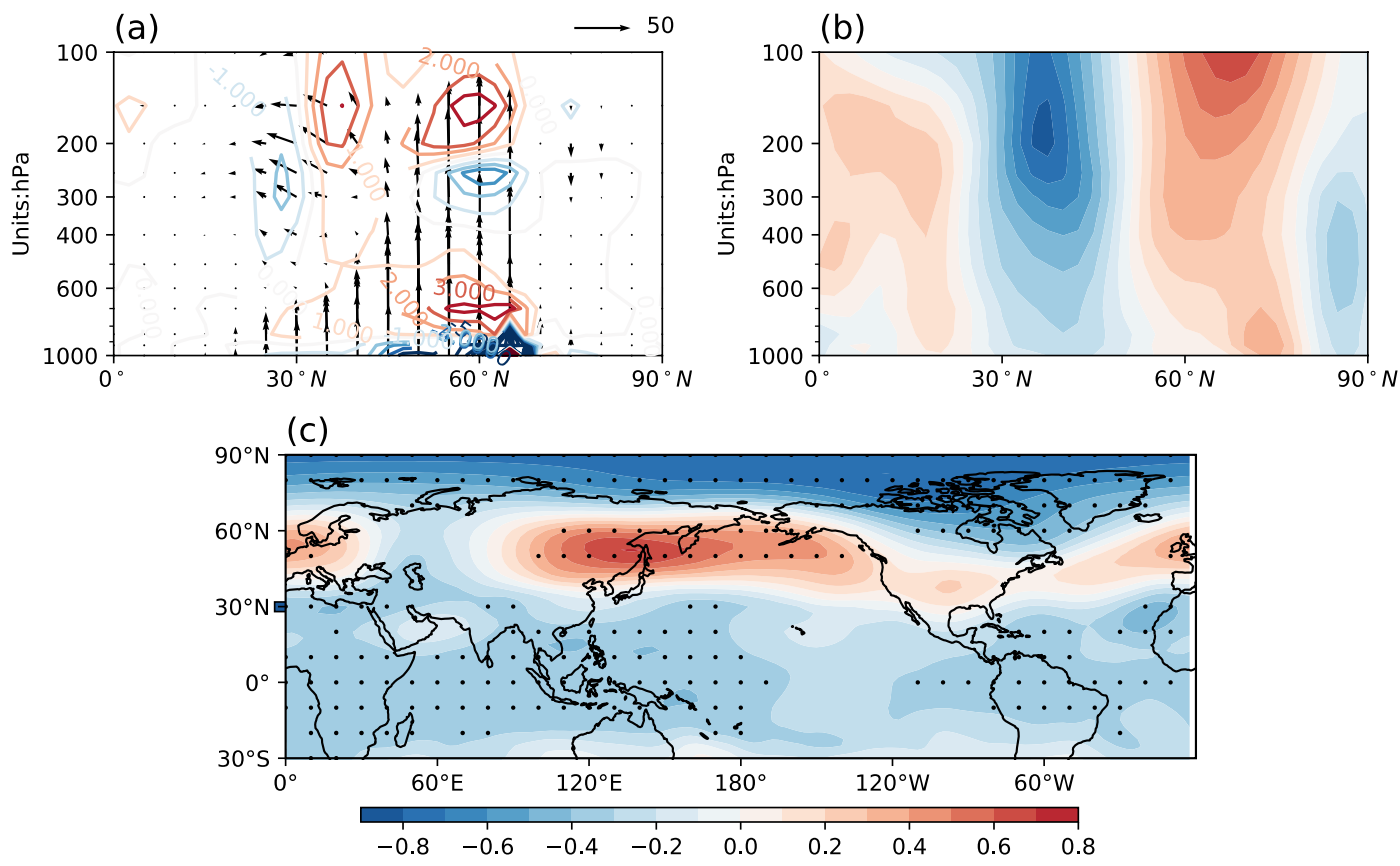

Fig.7 Synthesis of persistent freezing rain and snow events in southwest China in winter. a North Pacific $\left(120^{\circ} \mathrm{E}-120^{\circ} \mathrm{W}\right) \mathrm{EPF}$ (horizontal units: $107 \mathrm{~m}^{3} / \mathrm{s}^{2}$; vertical units: $\left.105 \mathrm{~m}^{3} / \mathrm{s}^{2}\right)$ and flux divergence field $(\mathrm{m} / \mathrm{s} /$ day $)$. b North Pacific $\left(120^{\circ} \mathrm{E}-120^{\circ} \mathrm{W}\right)$ zonal wind anomalies. c Correlation coefficient between the average zonal wind at $\left(70^{\circ} \mathrm{N}, 120^{\circ} \mathrm{E}-120^{\circ} \mathrm{W}\right)$ at an altitude of $200 \mathrm{hPa}$ in winter. Dots indicate passing the significance test of $\alpha=0.01$.

\section{3) Atmospheric Forcing in Key Areas of the Indian Ocean SST}

Similar to the impact of the cold SST in the tropical Pacific on the local Hadley circulation, consistent cold SST forcing in the Indian Ocean in the previous November weakened the Hadley circulation. The sinking branch of the Hadley circulation weakened at about $30^{\circ} \mathrm{N}$ in the Asia-western Pacific Ocean region and the sinking branch of the Hadley circulation inhibited upward movement in front of the southern branch trough (MQ Suo, 2009). To further verify this deepening effect of the Indian Ocean cold SST on the southern branch trough, we calculated the correlation coefficient between the SST3 index of the Indian Ocean cold SST region and the winter southern branch trough strength index in November $(-0.629)$, which passed the significance test at $\alpha=0.01$. The Indian Ocean SST in November therefore had a role in regulating the southern branch trough in winter. When the Indian Ocean SST was cold (warm), the southern branch trough deepened (weakened), affecting the transport of water vapor in southern China. 


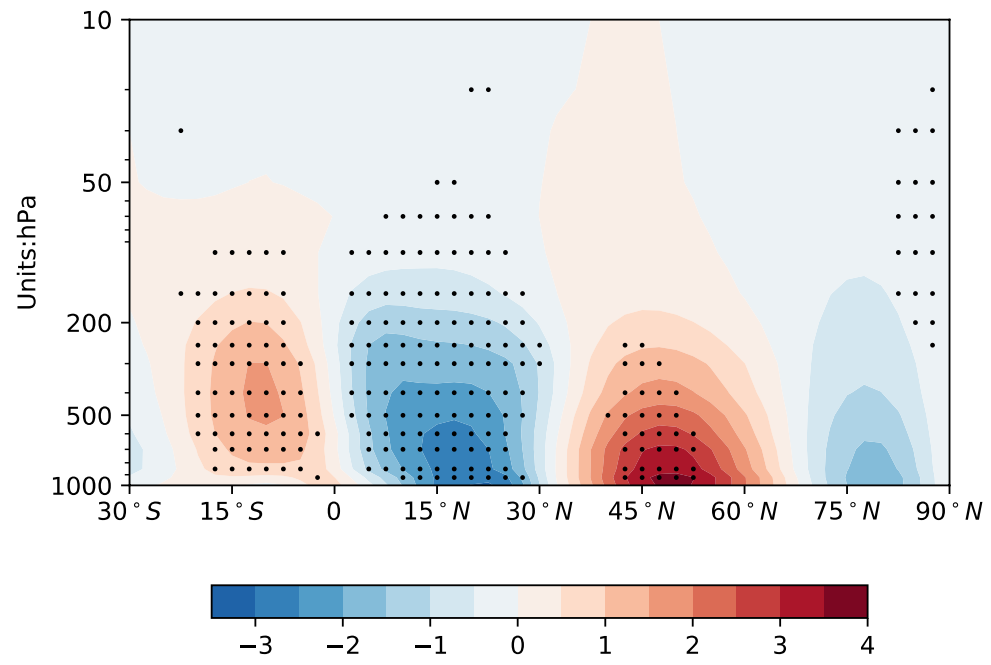

329

Fig.8 SST3 index in the cold SST region of the Indian Ocean in November regressed upon the winter Asiawestern Pacific $\left(60^{\circ} \mathrm{E}-180^{\circ}\right)$ mean current function anomaly field (units: $\left.10^{10} \mathrm{~kg} / \mathrm{s}\right)$. Dots indicate passing the

$$
\text { significance test of } \alpha=0.01 \text {. }
$$

\subsection{Forcing Mechanism of the November SST Anomaly on the Winter}

\section{Atmosphere}

We used the CESM1.2.2 sea-atmosphere coupling model to conduct sensitivity experiments on forcing outside the three key areas of the SST in November. The model was driven by the monthly average SST observed over 20 years and the SST was superimposed on the key area anomalies in November. Six to 20 years were taken after the model stabilized.

The model simulation results showed that after the November SST anomalies in the three key areas were superimposed, significant atmospheric circulation anomalies appeared in winter. The region from Alaska to Greenland (about $60^{\circ} \mathrm{N}$ ) at a height of $300 \mathrm{hPa}$ showed a negative disturbance of the geopotential height with the center located in western North America. The north Atlantic coast of North America at $30^{\circ} \mathrm{N}$ and Europe at $60^{\circ} \mathrm{N}$ both showed positive height disturbances (Fig10a). The atmospheric circulation anomalies from North America to Europe were consistent with the statistical results for the persistent freezing rain and snow events in southwest China during years with strong atmospheric geopotential height anomalies. XJ Sun et al. (2021) showed that the development of this anomalous circulation in the Atlantic Ocean in winter and its downstream dispersion increased the Mongolian high-pressure region and deepened the southern branch trough, which eventually led to continuous freezing rain and snow events in southwest China. The CESM model showed that the simulated lower temperatures and higher precipitation in southern China in winter increased disturbances in the SST (Fig10bc). This showed that abnormal SSTs in key areas in November can be regarded as inter-seasonal precursor signals for persistent freezing rain and snow events in southwest China. 


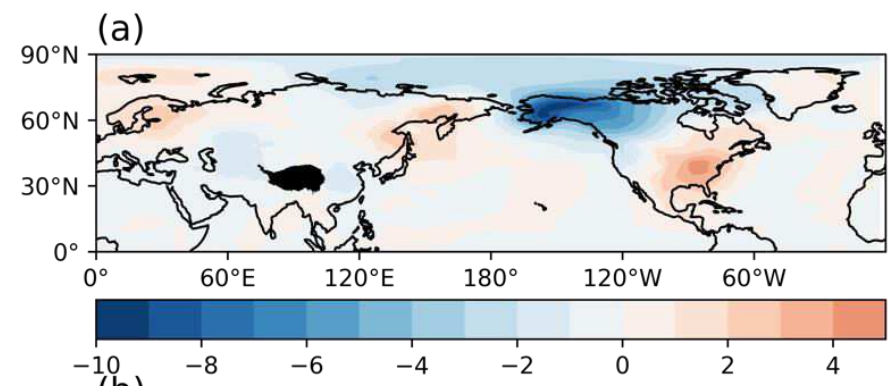

(b)

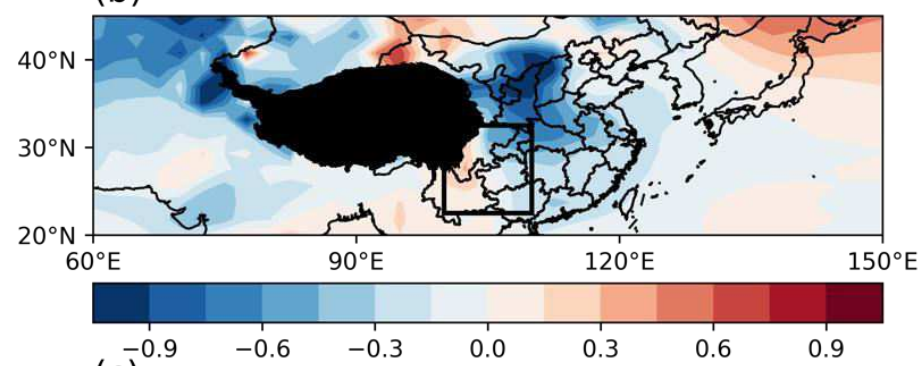

(c)

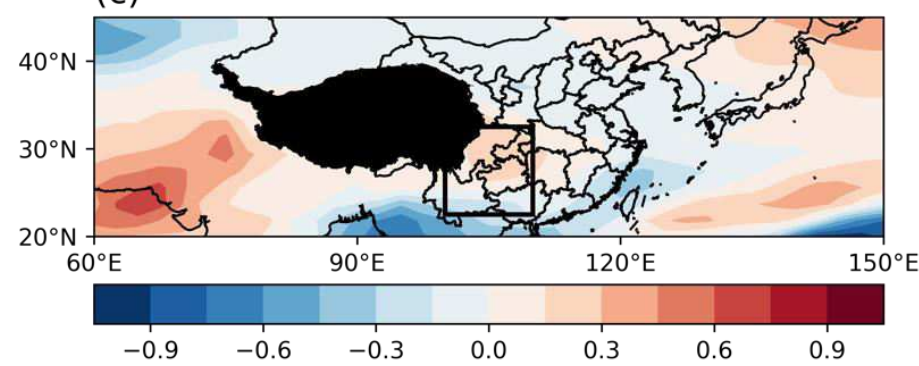

Fig.9 Simulation results for the CESM sea-atmosphere coupling model of inter-seasonal precursor signals of events. a 15-year average geopotential height of $300 \mathrm{hPa}$ in winter. b 15 -year average temperature in winter.

c 15 -year average precipitation in winter. Shading is the difference between the simulation results after the initial SST field signal was superimposed and the control group (the initial SST field)

\section{$358 \quad 3.4$ Cross-seasonal forecast index}

According to the above results on the correlation between the key SST regions and the key winter anomaly combination index and the discussion of the physical mechanism of the November SST anomaly mode on the winter atmospheric forcing, anomalous forcing of the SST from autumn to winter affected the atmosphere, causing significant anomalies in the atmospheric circulation in winter. Changes in the local atmospheric circulation affected the atmospheric circulation factors in East Asia through the meridional circulation and upstream and downstream effects (the Mongolian high pressure and the southern branch trough). An abnormally strong Mongolian high pressure in winter favored the diffusion of cold air from high to low latitudes, whereas abnormal activity of the southern branch trough favored the transport of water vapor in the south. Strong persistent freezing rain and snow events could then occur when the cold and warm air masses converged in southwestern China. Fig10 shows that the SST1, SST2, and SST3 indexes in November had a significant negative correlation with the PT index in southwest China in winter. In November, the tropical Pacific cold (warm) SST, the north Pacific PDO-like cold (warm) phase and the Indian Ocean uniformly cold (warm) SST led to a relatively large (small) winter PT index, the temperature was relatively low (high) and the precipitation was relatively high (low). This could lead to strong persistent freezing rain and snow events in southwest China. 


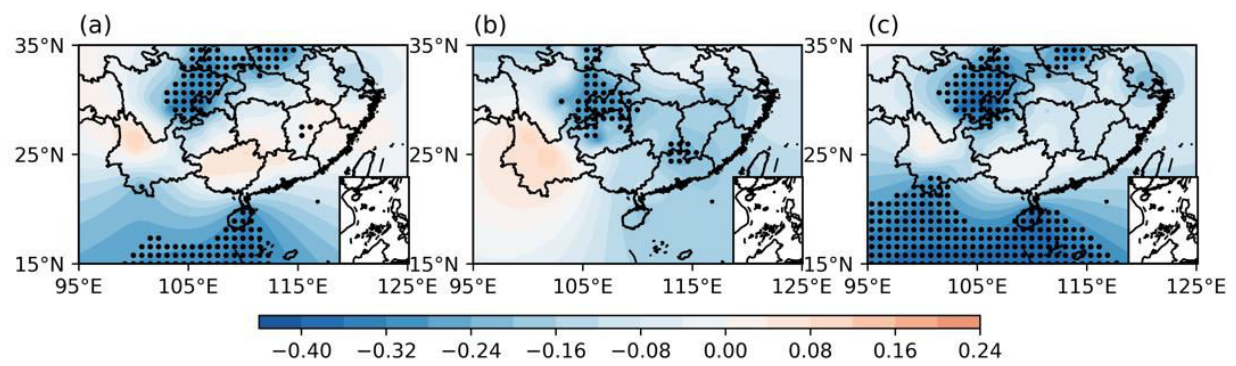

Fig.10 Correlation of the November a SST1 index, b SST2 index and c SST3 index with the southern PT index in winter. Dots indicate passing the significance test of $\alpha=0.01$

The winter key anomaly combination index and the SST1, SST2 and SST3 indices in November can be used to define the inter-seasonal SST forecast index:

$$
I_{s S t}=\left(-\widetilde{P}_{S S T 1}^{\prime}-\widetilde{P}_{S S T 2}^{\prime}-\widetilde{P}_{S S T 3}^{\prime}\right) / 3
$$

$\widetilde{P}_{S S T 1}^{\prime}, \widetilde{P}_{S S T 2}^{\prime}$, and $\widetilde{P}_{S S T 3}^{\prime}$ are the standardized series of the SST1, SST2 and SST3 SST indices, respectively, and $I_{s S t}$ is the inter-seasonal SST prediction index. The correlation coefficient between the prediction index and the key anomaly combination index was 0.560 , which passed the significance test of reliability at $\alpha=0.01$ (Figure 11). The key anomaly combination index of nine of the 13 severe freezing rain and snow events in southwest China and nine of the 13 cross-seasonal SST prediction indices were large and there was a good correlation between the two indices. The key anomaly combination index in winter increased when the SST prediction index increased in autumn, especially in November.

The SST anomaly in the previous autumn regulated the changes in temperature and precipitation in southwest China by affecting the high pressure in Mongolia and the activity of the southern branch trough in winter. To verify the predictive ability of the November SST anomaly for cooling and precipitation in southwest China, we calculated the correlation coefficient between the inter-seasonal prediction index $I_{s s t}$ and the average PT index in southern China in winter (Fig12). There was a positive correlation between $I_{s s t}$ and the average PT index in southern China, except for northwestern Yunnan and significant related centers in Sichuan, Chongqing, Guizhou, Hubei, Henan, Jiangsu and Zhejiang. The coupled development of the cold SST anomaly in the tropical Pacific in November, the PDO-loke cold phase SST in the north Pacific, and the Indian Ocean cold SST, favored lower temperatures and increased precipitation in southern China (mainly in the southwest) in winter (Fig12). 


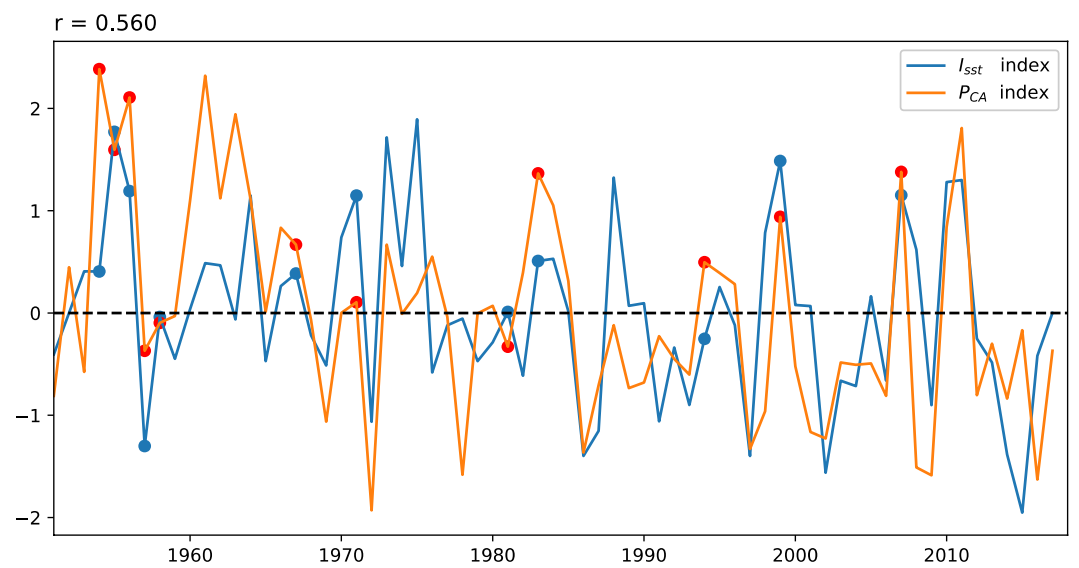

396

397

398

399

400

401

402

403

404

405

406

407

408

409

410
Fig.11 Key anomaly combination index and cross-seasonal SST forecast index in winter. The points represent strong years of freezing rain and snow events in southwest China.

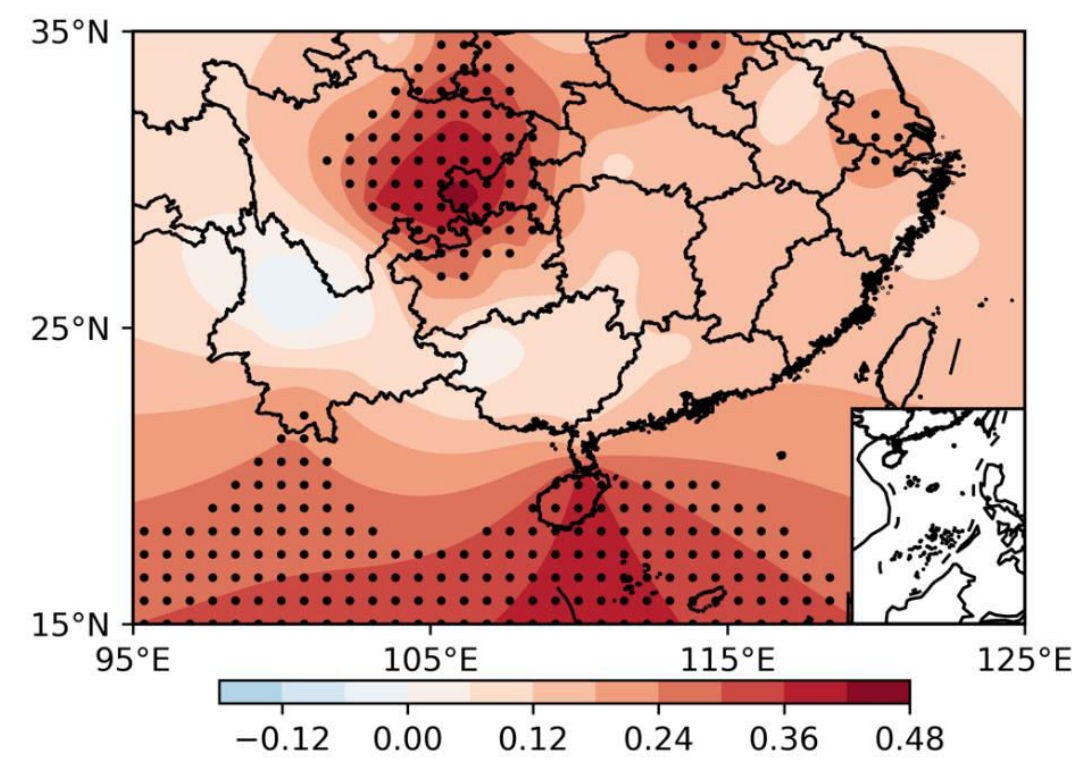

Fig.12 Correlation between the cross-seasonal forecast index and the southern winter average PT index.

Dots indicate passing the significance test of $\alpha=0.01$.

\section{Conclusion and discussion}

Fig13 shows that the cold SST in the tropical Pacific in the previous autumn, the north Pacific PDO-like cold phase SST mode and the Indian Ocean cold SST were all significantly correlated with the key winter anomaly combination index. These three causes of significant atmospheric circulation anomalies in the North Pacific and its lower reaches were coupled in winter.

The early development of La Niña favored enhancement of the Walker circulation and weakening of the Hadley and Ferrer circulations. As a result, the East Asian tropical-subtropical negative geopotential height was 
411 highly developed and a high-latitude anticyclone circulation developed in East Asia (Aleutian region), favoring 412 strengthening of the northerly winds in East Asia.

413 The colder PDO-like SST modes in the northeastern north Pacific Ocean and the warmer waters in the 414 southwest favored the development of a mid-latitude cyclonic circulation in the North Atlantic troposphere and 415 a high-latitude anticyclone circulation. In conjunction with weakening of the rising branch of the Ferrer 416 circulation caused by La Niña, the anomalous anticyclonic circulation in the mid-and upper layers of the 417 Aleutian deepened further. The SST forced the excitation of wave energy to upload, the wave energy diverged 418 in the mid- and upper troposphere at high latitudes and the westerly wind accelerated. This forced the polar 419 vortex to develop downstream and the North American trough deepens.

420 The cold SST in the Indian Ocean weakened the Hadley circulation from the Indian Ocean to East Asia, 421 favoring strengthening of the upward movement of the southern branch trough and deepening of the southern 422 branch trough.

423 The CESM sea-atmosphere coupling model was used to simulate the forcing effect outside the three key 424 areas of SST in November. The results showed that, after the increase of the SST in the three key areas in 425 November, the tropospheric atmospheric circulation anomalies in winter were consistent with the observed statistical results. The temperature in southern China was relatively low and precipitation relatively high, verifying that the key areas of SST were a cross-seasonal precursor signal for the occurrence of these events.

The SST prediction index $I_{\text {sst }}$ can be established based on the average SST anomaly in the key areas of SST in the previous November. The November $I_{s s t}$ index has a significant positive correlation with the winter average PT index in southwest China and therefore has a cross-seasonal significance in forecasting.

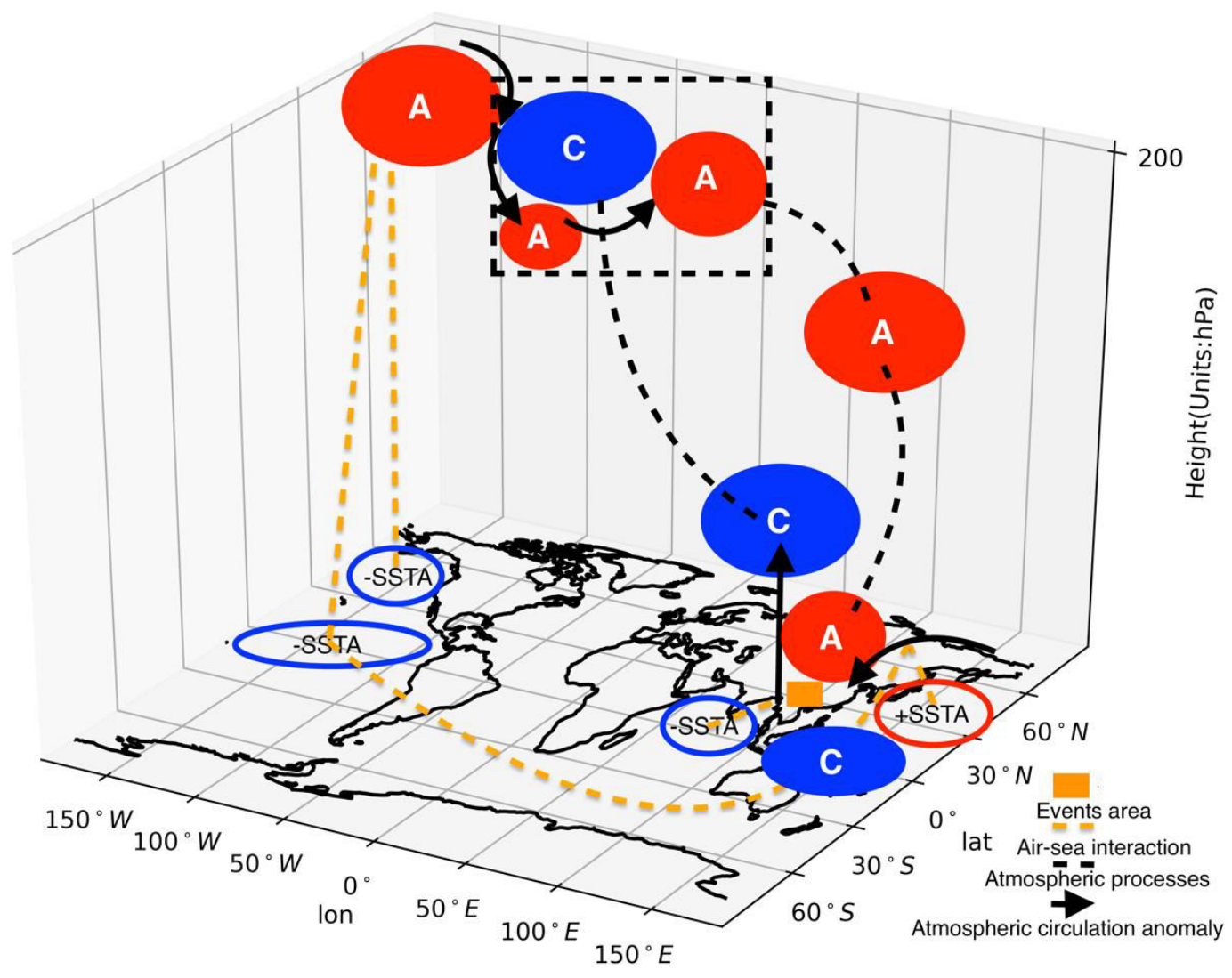


434 Acknowledgments We are grateful to the four anonymous reviewers for providing the valuable and insightful comments, which dramatically polish this manuscript.

436

437 Funding This work was supported by the National Key Research and Development Program of China (Grant No. 2018YFC1505602), the National Natural Science Foundation of China (Grant No. 41705055, 41505088), the Project of Scientific Creation of Post-Graduates of Jiangsu (Grant No. CXZZ12_0485), the Creative Teams of Jiangsu Qinglan Project and the Priority Academic Program Development of Jiangsu Higher Education Institutions (PAPD).

442

443 Data Availability Statement Listed in Sect. 2. Data and Methodology

444

Code availability Upon request

446

\section{References}

Bo S, Wang HJ, Zhou BT. Climatic Condition and Synoptic Regimes of Two Intense Snowfall Events in Eastern China and Implications for Climate Variability. Journal of Geophysical Research: Atmospheres, 2019, 124(2).

Bueh CL, Ji LR. On the Medium-Range Process of the Rainy, Snowy and Cold Weather of South China in Early 2008 Part I: Low-Frequency Waves Embedded in the Asian-African Subtropical Jet. Climatic and Environmental Research, 2008, 13(4):419-433.

Ding YH, Wang ZY, Song YF, et al. Causes of the rare low temperature rain and snow freezing disaster in January 2008 in southern China and its relationship with climate warming. 2008:158-175.

Du XL, Gao ST, Peng F. Study on the Cause of Continuous Low Temperature Rain and Snow Freezing Weather in Guizhou in Early 2011. Chinese Journal of Atmospheric Sciences, 2014, 38(001):61-72.

Gao H, Chen LJ, Jia XL, et al.. Analysis of large-scale low-temperature rain and snow freezing disaster in China in January 2008 II. Analysis of cause. Weather, 2008 (4): 101-106.

460 Gu L, Wei K, Huang RH. Relationship between Severe Low Temperature Freezing Disaster and East Asian Monsoon System Anomalies in January 2008 in China. Climatic and Environmental Research, 2008,

463 He JH, Sun XJ. The 34th annual meeting of the Chinese Meteorological Society. 0.

464 Jia XL, Zhao ZG, Li WX, et al. Journal of Applied Meteorology, 2013, 24(006):641-655. (in Chinese with $465 \quad$ English abstract)

466 Jiang M, Yu TT, Qian WH. Chinese Journal of Atmospheric Sciences, 2014, 38(004):813-824. (in Chinese)

467 Li CY, Yang H, Gu W. Climatic and Environmental Research, 2008(02):113-122. (in Chinese) 
Ji LR, Bueh CL, Shi N. On the Medium-Range Process of the Rainy, Snowy and Cold Weather of South China in Early 2008 Part III: Pressure Trough over the Tibetan Plateau/Bay of Bengal. Climatic and Environmental Research, 2008.

Li WX, Zheng ZH, Sun CH. Advances in the research and application of dynamic similarity prediction methods in short-term climate prediction in China in recent years. Chinese Journal of Atmospheric Sciences, 2013, 37(002):341-350.

Li Y, Wang SG, Jin RH, et al. Analysis of anomalous characteristics of blocking high during freezing rain and snow disaster in southern China. PLATEAU METEOROLOGY, 2012, 31(1):94-101.

Liao C. Circulation Typing Characteristics of Persistence Low Temperature Rain and Snow Freezing Events in South China. Chinese Academy of Meteorological Sciences.

Liu QQ, Wang PX, Xu XD, et al. Journal of Tropical Meteorology, 2011, 27(6):889-898. (in Chinese with English abstract)

Liu XM, Gao AN, Zhao JB. Characteristics and causes of freezing disasters of low temperature rain and snow in western South China in 2011. Journal of Natural Disasters, 2013, 22(06):232-239.

Ma JH, Wang PX, Li LP, et al. The relationship between "snow disaster in South China 0801" and medium-term high-pressure activity in the same period in Mongolia. Chinese Journal of Atmospheric Sciences, 2010, 32(5):652-660.

Qian X, Zhai PM. Analysis of low temperature rain, snow and freezing events and their variation characteristics in mainland China//Innovation-driven development to improve meteorological disaster prevention ability -S2 disaster weather monitoring, analysis and forecast. 2013.

Qian X. Low temperature rain and snow events in central and eastern China in January 2018 and their comparative analysis with 2008// The 35th Annual Meeting of Chinese Meteorological Society S1 Disaster Weather Monitoring, Analysis and Forecast, 2018. (in Chinese with English abstract)

Qian JL, 21 Department of Atmospheric Sciences, Physics S O , et al. Frontal genesis of moisture atmosphere during the early 2008 persistent freezing-rain event in southern China. Science China(Earth Sciences), 2010.

Qin J, Pan LN. Effect of combination of south branch trough and strong cold air on winter weather in Yunnan. METEOROLOGY, 1991, 17(003):39-43.

Shi N, Bueh CL, Ji LR, et al. Analysis of the mid-term process of rain and snow low temperature weather in South China in early 2008 II: Characteristics of the western Pacific subtropical high. Climatic and Environmental Research, 2008(04):434-445.

Tao SY, Wei J. Severe Snow and Freezing-Rain in January 2008 in the Southern China. Climatic and Environmental Research, 2008.

Sun XJ, Li SY, Yu YY, et al. Climatic characteristics of persistent frozen rain and snow events in southern China during the winter 1951-2017 and their relationship with the combinational anomaly of circulation. Chinese Journal of Atmospheric Sciences, to be published.

Sun XJ, Wang PX, Zhi H, et al. Analysis and comparison of several circulation indexes of Mongolian high and its correlation with winter temperature anomaly in China. Plateau Meteorology, 2010, 029(006):1493-1500. in winter half year. Chinese Journal of Atmospheric Sciences, 2009, 033(003):425-442. 
508 Wang L, Gao J, Zeng B. Spatial-temporal distribution and causes of low temperature rain and snow events in 509 southern China. Plateau and Mountain Meteorology Research, 2016(36):39-43. (in Chinese)

510 Wang HJ, Qin J, Zhang J. Resources and Environment in the Yangtze Basin, 2010, 19(7):839.

511 Wang L, Qin J, Chen ZH, et al. Statistical analysis of circulation and anomaly of meteorological elements in 512 freezing rain and snow disaster years in South China. Resources and Environment in the Yangtze Basin, $5132011(\mathrm{~S} 1): 173-180$.

514 Wang L. Analysis of Atmospheric Circulation Anomaly in Snow and Ice Disaster Weather in South China. 515 China University of Geosciences (Wuhan).

516 Wang L, Gao G, Zhang Q, et al. Analysis of large-scale cold rain and snow freezing disaster in China in January 5172008 I. Climate characteristics and impact assessment. The weather.

518 Wang PX, Lu CH, Guan ZY, et al. Journal of Nanjing Institute of Meteorology, 2007, 30(6):730-735. (in $519 \quad$ Chinese)

520 Wang, Yi, Yan, et al. Trends in Seasonal Precipitation over China during 1961-2007. Atmospheric and Oceanic $521 \quad$ Science Letters, 2009, 2(3):165-171.

522 Wang D, Liu C, Liu Y, et al. A Preliminary Analysis of Features and Causes of the Snow Storm Event over the 523 Southern Areas of China in January 2008[J]. Journal of Meteorological Research, 2009, 23(3):374-386.

524 Xiong, Zhe, Xiong, et al. Simulation of a Freezing Rain and Snow Storm Event over Southern China in January 2008 Using RIEMS 2.0. Atmospheric \& Oceanic Science Letters, 2013.

526 Yao R, Xu L, Zhang H, et al. Comparative Analysis of Causes and Effects of Two Low Temperature Rain and 527 Snow Freezing Disasters in Hunan Province in 2008/2011. Journal of Catastrophe, 2012(04):75-79.

528 Zhang CY, Zhang YC. Characteristics of the upper-level jet stream over East Asia during the continuous 529 low-temperature rain-snow freezing event in early 2008. Journal of Tropical Meteorology,

530 2013(02):306-314.

531 Zhang H, Qin J, Yun L. Climatic background of cold and wet winter in southern China: part I observational 532 analysis. Climate Dynamics, 2011, 37(11-12):2335-2354. 